Georgia State University

ScholarWorks @ Georgia State University

7-24-2020

\title{
Development of a Global Index Measuring National Policy Commitments to HIV Prevention and Treatment among People Who Inject Drugs
}

\author{
Eric L. Sevigny \\ Georgia State University, esevigny@gsu.edu \\ Peter Meylakhs \\ National Research University Higher School of Economics, pmeylakhs@hse.ru \\ Mohammad Javad Feizollahi \\ Georgia State University, mfeizollahi@gsu.edu \\ Mohamad Reza Amini \\ Tarbiat Modares University, Mohamadreza.Amini@modares.ac.ir
}

Follow this and additional works at: https://scholarworks.gsu.edu/cj_facpub

Part of the Criminology and Criminal Justice Commons

\section{Recommended Citation}

Sevigny, Eric L.; Meylakhs, Peter; Feizollahi, Mohammad Javad; and Amini, Mohamad Reza, "Development of a Global Index Measuring National Policy Commitments to HIV Prevention and Treatment among People Who Inject Drugs" (2020). CJC Publications. 30.

https://scholarworks.gsu.edu/cj_facpub/30

This Article is brought to you for free and open access by the Department of Criminal Justice and Criminology at ScholarWorks @ Georgia State University. It has been accepted for inclusion in CJC Publications by an authorized administrator of ScholarWorks @ Georgia State University. For more information, please contact scholarworks@gsu.edu. 


\section{Measuring National Commitments to HIV Prevention and Treatment among People Who Inject Drugs}

\section{Authors}

Eric L. Sevigny, Ph.D., Department of Criminal Justice and Criminology, Georgia State University, Atlanta, GA, USA, esevigny@gsu.edu

Peter Meylakhs, Ph.D., Laboratory for Comparative Social Research, National Research University Higher School of Economics, Saint Petersburg, Russian Federation, pmeylakhs@hse.ru

Mohammad Javad Feizollahi, Ph.D., Business Analytics, Robinson College of Business, Georgia State University, Atlanta, GA, USA, mfeizollahi@gsu.edu

Mohamad Reza Amini, Ph.D., Systems Management, Management and Economic Department, Tarbiat Modares University, Tehran, Iran, Mohamadreza.Amini@modares.ac.ir.

\section{Keywords}

HIV prevention and treatment; injection drug use; composite indicators; data envelopment analysis; benchmarking and performance assessment; comparative policy analysis 


\section{Abstract}

Background: People who inject drugs (PWID) around the world are disproportionately affected by the HIV epidemic. National policy responses to the epidemic heavily influence risk factors for HIV acquisition among this key group. Prior efforts to monitor national policy responses to HIV/AIDS among PWID were limited both in scope and coverage. In this paper we develop and validate the HIV-PWID Policy Index (HPPI) to benchmark and monitor national commitments to HIV prevention and treatment among PWID.

Methods: Composite indicator was constructed employing fuzzy multilayer data envelopment analysis (FMLDEA). Model inputs based on data from 105 countries included 27 variables measured across six conceptual domains, including needle and syringe programs, opioid substitution treatment, testing and counseling, information and education, monitoring and evaluation, and legal and policy climate.

Results: According to the HPPI, the top performing countries in commitment to HIV prevention and treatment among PWID were Spain (0.988), Switzerland (0.982), Luxembourg (0.970), Moldova (0.970), and Kyrgyzstan (0.945), whereas the poorest performing included Nicaragua (0.094), Japan, (0.094), Cape Verde (0.097), Syria (0.174), and Benin (0.185). Regionally, commitment to HIV services targeting PWID was highest among European countries $(0.81)$ and lowest among African countries (0.50), with Oceania (0.76), Asia (0.66), and the Americas (0.56) in the mid-range. Subregional differences were even more prominent, with West and Central European nations (0.84) and Central American nations (0.22) earning the highest and lowest HPPI scores, respectively.

Conclusions: The HPPI documented substantial national and regional variation in policy responses to the HIV epidemic among PWID. Our analysis also revealed that many countries have limited HIV/AIDS data collection and monitoring capabilities. Continued enhancement and standardization of global HIV/AIDS monitoring efforts are therefore vital to articulated 
national and international benchmarking and performance assessment goals. 


\section{Introduction}

Injection drug use is a major global public health issue. There are an estimated 15.6 million people worldwide who inject illicit drugs each year, and about one in six of these individuals live with HIV (Degenhardt, et al., 2017). People who inject drugs (PWID) are 24 times more likely to acquire HIV than people in the general population, with new HIV infections among PWID continuing to climb in many regions of the world (UNAIDS, 2015a, 2016).

National educational, prevention, treatment, and legal responses to the problem of injection drug use heavily influence both the macro and micro risk factors for HIV acquisition among PWID. Investments in evidence-based prevention and treatment interventions - such as opioid substitution, needle exchange, and antiretroviral therapy—can substantially curtail the spread of HIV among PWID (Strathdee, et al., 2010). However, only about half the world's countries implement evidence-based harm reduction policies aimed at preventing the spread of HIV among PWID (Harm Reduction International, 2016), and many others continue to subject this population to punitive criminal justice measures and other counterproductive responses (Lunze, et al., 2014; Strathdee, Beletsky, \& Kerr, 2015).

In reaffirming international efforts to end the HIV/AIDS epidemic by 2030 , the UN General Assembly adopted the Political Declaration on HIV and AIDS (United Nations, 2016). UNAIDS has set a goal of achieving 90\% access to PWID-tailored HIV prevention services by 2020, including HIV testing, antiretroviral therapies (ART), needle and syringe exchange programs (NSPs), opioid substitution therapy (OST), safe sex programming, education and outreach, and related clinical services (UNAIDS, 2015b). Systematic reviews of the global epidemiology of HIV/AIDS among PWID and the associated global, regional, and national policy responses emphasize the need for comprehensive monitoring and assessment tools to achieve these objectives (e.g., Mathers, et al., 2010; Mathers, et al., 2008). Indeed, Beyrer, et 
al. (2010) articulated a specific need for a national HIV/AIDS accountability matrix to document country-level interventions targeting PWID (see also Degenhardt, et al., 2014). Toward this end, the current study develops the HIV-PWID Policy Index (HPPI), which is the first global policy index measuring national commitments to HIV/AIDS prevention and treatment interventions for PWID. During the last decade, many composite indexes (CIs) have been developed in the domains of economics, governance, security, environment, sustainability, and public health (Botero, Nelson, \& Pratt, 2011; Moxham-Hall \& Ritter, 2017; Pissourios, 2013). The proliferation of these types of CIs is an indication of their importance for performance evaluation, benchmarking, and decision-making.

\section{Previous HIV/AIDS Policy Monitoring Efforts}

Several prior efforts have been undertaken to monitor national policy responses to HIV/AIDS, but they remain limited in scope and coverage with respect to PWID. Desmond and colleagues (2008) developed an early model to rank country efforts against HIV/AIDS based on three narrowly targeted indicators (prevention of mother-to-child HIV transmission, antiretroviral treatment coverage, and the ratio of orphans to non-orphans attending school). The AIDS Accountability Country Scorecard (AIDS Accountability International, 2008) represents a more comprehensive effort based on monitoring data across eight domains (data collection, at-risk populations, treatment, prevention, coordination, civil society, financing, and human rights). Individual country scores were not reported, however, limiting the scorecard's utility for informing national strategic responses.

Other monitoring efforts have developed composite indexes (CIs) that aggregate different policy indicators into a single score. The AIDS Program Effort Index (API) measures levels of national HIV programming and support for 54 countries across ten policy domains (political support; policy and planning; organizational structure; program resources; evaluation, monitoring, and research; legal and regulatory environment; human rights; 
prevention programs; care and treatment services; and mitigation programs) (Stover, 2001; see also USAID, UNAIDS, WHO, \& the POLICY Project, 2003). Alfven, et al. (2014) developed the HIV Monitoring and Evaluation System Capacity Index (MESCI) based on reports for 78 countries measuring national HIV commitments, government engagement, partner/civil society engagement, and data generation. None of these prior indices, however, focus on the target population of PWID that motivates the current study.

To our knowledge, the Policy Environment Index for PWID (PEIP) is the only monitoring effort that addresses the HIV/AIDS policy environment for injection drug users (Platt, et al., 2015). The index is based on six indicators measured across three domains: meaningful engagement of stakeholders (evidence of a national organization of drug users), coordinated national strategy for HIV prevention and drug use (evidence of explicit inclusion of harm reduction in national-level strategy, monitoring/evaluation studies documenting HIV among PWID), and evidence-based HIV prevention intervention approaches (presence of OST and NSP, presence of OST and NSP in prison settings, evidence of decriminalization of drug possession and use). PEIP was constructed for 50 European region countries, with higher (lower) index scores suggesting an enabling (constraining) policy environment for HIV prevention among PWID. Although representing a step forward in measuring commitments to HIV prevention and treatment among PWID, PEIP is based on a small number of indicators for European countries. In developing the HIV-PWID Policy Index (HPPI), the current study aims to extend prior research by expanding the number of underlying indicators, increasing coverage to more world regions, and presenting individual results for each country.

\section{Methods}

Construction of the HPPI proceeded in several steps. First, we developed a conceptual framework to guide the identification of domains and selection of policy indicators for constructing the HPPI. Second, we reviewed the quality and availability of country-level 
indicators, while also addressing missingness and normalization concerns. Third, we employed fuzzy multilayer data envelopment analysis (FMLDEA) to aggregate the indicators into a composite index, with higher scores reflecting a stronger commitment to HIV risk reduction among PWID. Each of these steps is discussed in more detail in the following sections.

\section{Conceptual Framework}

The HPPI conceptual framework was developed based on a comprehensive review of the evidence-based literature on HIV interventions targeting PWID and the first two authors' subject area expertise. Our conceptual framework comprises six policy domains: (1) Needle and Syringe Programs, (2) Opioid Substitution Treatment, (3) Testing and Treatment, (4) Information and Education, (5) Monitoring and Evaluation, and (6) Legal and Policy Climate. To populate the domains with relevant indicators, we examined data sources produced by leading international governmental (UNAIDS, UNODC, WHO, EMCDDA) and nongovernmental organizations (Harm Reduction International). We also reviewed relevant peer-reviewed publications and other reports for additional data. Table 1 presents the conceptual framework and associated indicators, with more detailed definitions and source information presented in Appendix I.

Domain 1, Needle and Syringe Programs (NSPs), captures traditional and prison-based syringe distribution programming with demonstrated effectiveness in reducing HIV transmission and other injection risk behaviors among PWID (Fernandes, et al., 2017; Gibson, Flynn, \& Perales, 2001; Wodak \& Cooney, 2006). We also include supervised injection facilities (SIFs) in this domain since these sites offer a host of services that promote safer injection conditions and practices that reduce rates of HIV infection among PWID (Andresen \& Jozaghi, 2012; Kennedy, Karamouzian, \& Kerr, 2017; Pardo, Kilmer, \& Caulkins, 2018; Pinkerton, 2011; Potier, Laprévote, Dubois-Arber, Cottencin, \& Rolland, 2014). Domain 1 also captures the domestic policy environment pertaining to the promotion of safe injection 
behaviors, which can influence the development and sustainability of NSP interventions (Hayle, 2018).

Domain 2, Opioid Substitution Treatment (OST), measures opioid agonist treatments that have been shown to be effective in reducing HIV infections and risky behaviors among injection drug users (Ahamad, et al., 2015; Karki, Shrestha, Huedo-Medina, \& Copenhaver, 2016; MacArthur, et al., 2012; Marks, et al., 2019), including in prison-based settings (Larney, 2010). The national policy stance toward OST among PWID is also measured in Domain 2, as political will and national commitments influence the ability to scale up OST interventions (Reid, Sharma, \& Higgs, 2014).

Testing and Treatment interventions are captured in Domain 3. Despite often poor treatment adherence among injection drug users (Lert \& Kazatchkine, 2007), detect-and-treat interventions can significantly reduce HIV transmission risk among PWID (Des Jarlais, et al., 2016; Montaner, et al., 2010). Consequently, national preventive strategies regarding HIV testing and counseling among PWID, as well as the accessibility of antiretroviral treatment (ART), are measured in this domain.

Domain 4, Information and Education, captures national policy efforts designed to improve health and reduce risky behaviors among PWID. Although the evidence regarding the health-promoting effects of mass media information, education, and communication efforts targeting PWID is not strong (Aggleton, Jenkins, \& Malcolm, 2005), social media and mobile health interventions are promising and require further investigation (Cao, et al., 2017; Genz, et al., 2015). Domain 5, Monitoring and Evaluation, captures national HIV monitoring and evaluation efforts, which are integral to understanding and shaping HIV interventions among PWID and other vulnerable populations (Alfven, et al., 2017; Gall, et al., 2017; Weir, et al., 2018). Finally, Domain 6, Legal and Policy Climate, captures aspects of the policy environment concerning both HIV and PWID, as de-stigmatization and decriminalization of these statuses 
can promote and reinforce effective prevention and treatment efforts (Baker, et al., 2019; DeBeck, et al., 2017; Strathdee, et al., 2015; Strathdee, et al., 2010).

\section{[INSERT TABLE 1 ABOUT HERE]}

\section{Assessment and Treatment of Indicators}

Across all indicators, we initially collected data on 181 countries. We dropped 76 countries from the analysis due to missing data on five or more policy indicators, resulting in a final analytic sample of $n=105$ countries. Among included countries, the ratio of missing to total data was just $1.4 \% .{ }^{1}$ We imputed data in these instances by taking either the modal value for binary indicators or using the average ratio method for continuous and ordinal data (Tamaddon, Jahanshahloo, Lotfi, Mozaffari, \& Gholami, 2009).

Next, we normalized the data to place all measures on a similar scale, which is a necessary step prior to index construction. We adopted the distance-to-reference approach, using the maximum reported indicator value as the reference for continuous and ordinal data; binary data were not normalized (see Organisation for Economic Co-operation and Development, 2008).

\section{Constructing the HIV-PWID Policy Index}

Recent progress in the development of CIs includes both objective methods and subjective methods (Greco, Ishizaka, Tasiou, \& Torrisi, 2019). A common feature of many of these methods is the assumption of uniform indicator weights for the DMUs under study, which ignores the relative 'importance' of each indicator and makes it difficult to ascertain unitspecific predictors of performance. In this respect, data envelopment analysis (DEA) offers several advantages over other CI construction methods. First, DEA can be used to combine multiple indicators without prior knowledge of their trade-offs, i.e., weights. Second, DEA

\footnotetext{
${ }^{1}$ The percentage of missing data by indicator was $0 \%$ except as follows: v1.2 (8.6\%), v3.2 (5.7\%), v5.2 (4.8\%), v6.1 (7.6\%), v6.3 (1.9\%), v6.4 (1.0\%), v6.6 (1.0\%), v6.7 (1.0\%), v6.8 (1.0\%), and v6.9 (4.8\%).
} 
evaluates the relative performance of DMUs to ensure that each unit obtains the best possible set of indicator weights (Cherchye, Moesen, Rogge, \& Puyenbroeck, 2007). Any other possible set of weights would produce a lower (i.e., less favorable) composite index score.

Applications of DEA for CI construction often focus on policy indicators. Basic DEA models assume that the data are both quantitative and nonhierarchical. Neither of these assumptions holds for the current study. To combine both quantitative and qualitative data, we follow Shen and colleagues (Shen, Hermans, Brijs, \& Wets, 2014; Shen, Ruan, et al., 2011) in implementing a fuzzy DEA approach that interprets qualitative data as fuzzy numerical values, which can be incorporated into the model with varying degrees of certainty, $h$. When $h=1$, qualitative data are treated as numerical and the results are equivalent to crisp DEA. When $h<1$, a more cautious approach is taken regarding measurement precision, resulting in a wider range of index scores for each country. Further, within each $h$ degree, we present three different scenario weights for each DMU in producing a set of pessimistic, indifferent, and optimistic index scores. To account for the hierachical nature of our conceptual framework, we follow Shen and colleagues (Shen, Hermans, Brijs, \& Wets, 2013; Shen, Hermans, et al., 2011) multilayer DEA model which incorporates different types of the possible weight restrictions for each domain. Integrating these two approaches produces a fuzzy multilayer DEA (FMLDEA) model. Finally, we employ a cross-efficiency extension to DEA developed by Sexton, Silkman, and Hogan (1986) to effectively rank the DMUs (i.e., countries) on performance. See Appendix II for technical details of these specifications. All models were solved with the optimization modeling software Lingo 13.0 (Lindo Systems, 2017).

\section{Results}

Country-level results of the FMLDEA-based CI model are presented in Table 2. CI scores are presented as the cross efficiency scores for the indifferent scenario for $h=0.5$, reflecting medium performance while incorporating some decision-maker uncertainty about 
the crispness of the data (see Appendix III for sensitivity analyses). The quartile distribution of these index scores is mapped in Figure 1. The discriminatory power of the model could be improved by imposing some restrictions on the indicator weights derived from expert opinion, but given that the scores derived from the cross-effeciency matrix provide good discrimination among the DMUs, we allow the weights to be calculated freely and directly by the model.

\section{[INSERT TABLE 2 ABOUT HERE]}

\section{[INSERT FIGURE 1 ABOUT HERE]}

The top-performing decile of countries include six from Europe (Spain, Switzerland, Luxemborg, Moldava, Norway, and France), three from Asia (Kyrgystan, Armenia, and India), and one each from the Americas (Canada) and Oceania (Australia). Conversely, the bottom performing decile of countries includes five from Asia (Maldives, Bahrain, Oman, Syria, and Japan), four from Africa (Seychelles, Libya, Benin, and Cape Verde), and two from the Americas (Honduras and Nicaragua).

Table 3 presents the mean HPPI scores by region, revealing that commitment to HIV services among PWID is highest among European countries, with index scores for each European subregion above the global mean index score (0.67). Among European countries, only Cyprus (0.65), Croatia, (0.64), Macedonia (0.57), and Turkey (0.46) had index scores below the global mean. Oceanic countries also recorded above-average index scores on commitment to HIV programming among PWID, an outcome driven by high-performing Australia (0.91). Overall, index scores from Asian countries were on par with the global average, but this average masks considerable subregional variation. Central Asian countries, for instance, are substantially higher performing (0.85) than Near and Middle East countries (0.33). Countries in the Americas recorded an average index score lower than the global mean, but this average also obscures substantial variation by subregion as indicated by the extremes reported for North America (0.82) and Central America (0.22). Lastly, both regionally and 
subregionally, African countries performed poorest on commitment to HIV programming among PWID, with no African subregion attaining a mean index score above the global average, despite certain individual African countries performing highly (e.g., top-20 ranked Mauritius and Morocco).

\section{[INSERT TABLE 3 ABOUT HERE]}

\section{Construct Validity of the HIV-PWID Policy Index}

The HPPI is broadly consistent with national and regional commitments to HIV prevention and treatment as indicated by a recent systematic review of available literature and data (Larney, et al., 2017). To more formally assess the construct validity of the HPPI, we compared our results with Platt et al.'s (2015) Policy Environment Index for PWID. As shown in Figure 2 for the 44 overlapping countries, there is a moderate sized positive correlation $(r=$ 0.51) between the two composite indicators. ${ }^{2}$ Although Platt et al. (2015) used six indicators across three domains compared to the 27 indicators across six domains used to construct the HPPI, the convergence of the two indices provides supporting evidence that the HPPI is measuring national commitments to HIV prevention and treatment among PWID.

\section{[INSERT FIGURE 2 ABOUT HERE]}

\section{Discussion}

The global prevalence of HIV and other infectious diseases among PWID has increased in recent years, with a growing list of countries documenting evidence of injection drug use (Degenhardt, et al., 2017). At the same time, effective interventions for preventing and treating HIV among PWID are being increasingly adopted by nations across the globe (Larney, et al., 2017). Still, reliable and comprehensive information about national implementation and local coverage of these interventions remains scarce, especially among vulnerable populations. While international agencies such as UNAIDS and WHO have greatly expanded monitoring

\footnotetext{
${ }^{2}$ Note that instead of reporting raw index scores, Platt et al. (2015) grouped scores into five ranked categories.
} 
and evaluation capabilities, few efforts have systematically documented country-level progress and commitments supporting the international goal of ending the HIV/AIDS epidemic by 2030 (UNAIDS, 2016).

Against this backdrop, the current study developed the HIV-PWID Policy Index (HPPI) to parsimoniously measure national commitments to HIV prevention and treatment interventions targeting PWID. Specifically, we marshalled 27 indicators across six conceptual domains and implemented an innovative fuzzy multiple layer data envelopment analysis (FMLDEA) model to summarize national efforts for 105 countries. Previous index construction efforts in this area used less robust methods, incorporated fewer measures, or focused on a smaller subset of countries. The HPPI thus stands as a promising new tool with utility for country-level performance evaluation, benchmarking, and decision-making for HIV interventions targeting PWID.

The HPPI documented substantial national and regional variation in policy responses to the HIV epidemic among PWID. Top performing countries on the HPPI clustered in several world subregions: Central Asia (0.85), West and Central Europe (0.84), Eastern Europe (0.83), and North America (0.82). High performance of Western European and North American countries might be explained by their sizable and entrenched numbers of PWID that necessitated and justified public health oriented and evidenced-based responses to the HIV epidemic among this population. High performace of Central and Eastern European countries might be attributable to the acuteness of the HIV epidemic among PWID following the collapse of the Soviet Union, together with national coordinating mechanisms (excepting Russia) that support the implementation of evidenced-based responses recommended by the major international public health bodies, such as WHO and UNAIDS.

In contrast, the poorest performing countries tended to be located in Southern Africa (0.48), West and Central Africa (0.38), Near and Middle East (0.33), and Central America 
(0.22). A partial explanation for poor policy performance in these regions could be that the numbers of PWID are relatively low-e.g. 0.12\% among people aged 15-64 years in the Middle East and North Africa, and $0.28 \%$ in the Sub-Saharan Africa compared to $1.30 \%$ in the Eastern Europe (Degenhardt et al., 2017). Accordingly, the HIV epidemic among PWID in countries of these regions may not be percevied as salient enough to warrant adopting domestic policies that are in accordance with international public health guidelines.

As a monitoring tool, the HPPI is only as reliable as the underlying data that goes into its construction. Measuring stigmatized behaviors and populations, including the associated policy responses that may not be officially sanctioned (e.g., needle exchange, safe injection sites), is challenging. Doing this well across dozens of countries is even more daunting, especially when high-level policies do not reflect what is actually happening on the ground or political considerations impede reporting to international agencies. As a case in point, Kyrgyzstan is ranked fifth on the HPPI because the government promotes evidence-based interventions targeting HIV prevention and treatment among PWID, including official support for NSPs. However, recent research has documented significant individual-level barriers to accessing NSP services by PWID in Kyrgyzstan (Deryabina \& El-Sadr, 2017), which are unlikely to be captured by national policy indicators. Another limitation of the HPPI is that the applied model cannot be used to decompose the rank of countries by domain. Nevertheless, country-level indicators are reported in a supplemental data file to enable detailed inspection and assessment of each nation's policy stance.

Our findings point to the urgent need for both country-specific and regional efforts to improve HIV prevention programming, treatment service delivery, and legal/policy environments for PWID. However, as demonstrated in the global heat map of the HPPI in Figure 1, countries from certain world regions, including much of sub-Saharan Africa and South America, have limited HIV/AIDS data and monitoring capabilities, highlighting regional 
opportunities for improving targeted data collection efforts. Continued enhancement and standardization of global HIV/AIDS monitoring efforts efforts are therefore vital to national and international benchmarking and performance assessment goals.

\section{Acknowledgements}

This paper was supported, in part, by the Russian Academic Excellence Project '5-100' granted to the second author. 


\section{References}

Aggleton, P., Jenkins, P., \& Malcolm, A. (2005). HIV/AIDS and injecting drug use: Information, education and communication. International Journal of Drug Policy, 16, 21-30.

Ahamad, K., Hayashi, K., Nguyen, P., Dobrer, S., Kerr, T., Schütz, C. G., Montaner, J. S., \& Wood, E. (2015). Effect of low-threshold methadone maintenance therapy for people who inject drugs on HIV incidence in Vancouver, bc, Canada: An observational cohort study. The Lancet HIV, 2, e445-e450.

AIDS Accountability International. (2008). The AIDS accountability country scorecard report. Stockholm: AIDS Accountability International.

Alfven, T., Erkkola, T., Ghys, P., Padayachy, J., Warner-Smith, M., Rugg, D., \& De Lay, P. (2017). Global AIDS reporting-2001 to 2015: Lessons for monitoring the sustainable development goals. AIDS and Behavior, 21, 5-14.

Alfven, T., McDougal, L., Frescura, L., Aran, C., Amler, P., \& Gill, W. (2014). A decade of investments in monitoring the HIV epidemic: How far have we come? A descriptive analysis. Health Research Policy and Systems, 12, 62.

Andresen, M. A., \& Jozaghi, E. (2012). The point of diminishing returns: An examination of expanding vancouver's insite. Urban Studies, 49, 3531-3544.

Baker, P., Beletsky, L., Avalos, L., Venegas, C., Rivera, C., Strathdee, S. A., \& Cepeda, J. (2019). Policing practices and HIV risk among people who inject drugs-a systematic literature review. Available at SSRN: https://ssrn.com/abstract=3401985 or http://dx.doi.org/10.2139/ssrn.3401985.

Beyrer, C., Malinowska-Sempruch, K., Kamarulzaman, A., Kazatchkine, M., Sidibe, M., \& Strathdee, S. A. (2010). Time to act: A call for comprehensive responses to HIV in people who use drugs. The Lancet, 376, 551-563.

Botero, J. C., Nelson, R. L., \& Pratt, C. (2011). Indices and indicators of justice, governance, and the rule of law: An overview. Hague Journal on the Rule of Law, 3, 153-169.

Cao, B., Gupta, S., Wang, J., Hightow-Weidman, L. B., Muessig, K. E., Tang, W., Pan, S., Pendse, R., \& Tucker, J. D. (2017). Social media interventions to promote HIV testing, linkage, adherence, and retention: Systematic review and meta-analysis. Journal of Medical Internet Research, 19, e394.

Cherchye, L., Moesen, W., Rogge, N., \& Puyenbroeck, T. (2007). An introduction to 'benefit of the doubt' composite indicators. Social Indicators Research, 82, 111-145.

DeBeck, K., Cheng, T., Montaner, J. S., Beyrer, C., Elliott, R., Sherman, S., Wood, E., \& Baral, S. (2017). HIV and the criminalisation of drug use among people who inject drugs: A systematic review. The Lancet HIV, 4, e357-e374.

Degenhardt, L., Mathers, B. M., Wirtz, A. L., Wolfe, D., Kamarulzaman, A., Carrieri, M. P., Strathdee, S. A., Malinowska-Sempruch, K., Kazatchkine, M., \& Beyrer, C. (2014). What has been achieved in HIV prevention, treatment and care for people who inject drugs, 2010-2012? A review of the six highest burden countries. International Journal of Drug Policy, 25, 53-60.

Degenhardt, L., Peacock, A., Colledge, S., Leung, J., Grebely, J., Vickerman, P., Stone, J., Cunningham, E. B., Trickey, A., Dumchev, K., Lynskey, M., Griffiths, P., Mattick, R. P., Hickman, M., \& Larney, S. (2017). Global prevalence of injecting drug use and sociodemographic characteristics and prevalence of HIV, HBV, and HCV in people who inject drugs: A multistage systematic review. The Lancet Global Health, 5, e1192e1207. 
Deryabina, A., \& El-Sadr, W. M. (2017). Uptake of needle and syringe program services in the Kyrgyz Republic: Key barriers and facilitators. Drug and Alcohol Dependence, 179, 180-186.

Des Jarlais, D. C., Arasteh, K., McKnight, C., Feelemyer, J., Hagan, H., Cooper, H. L., Campbell, A. N., Tross, S., \& Perlman, D. C. (2016). Providing ART to HIV seropositive persons who use drugs: Progress in New York City, prospects for "ending the epidemic". AIDS and Behavior, 20, 353-362.

Desmond, C., Lieberman, E., Alban, A., \& Ekström, A.-M. (2008). Relative response: Ranking country responses to HIV and AIDS. Health and Human Rights, 10, 105-119.

Fernandes, R. M., Cary, M., Duarte, G., Jesus, G., Alarcão, J., Torre, C., Costa, S., Costa, J., \& Carneiro, A. V. (2017). Effectiveness of needle and syringe programmes in people who inject drugs-an overview of systematic reviews. BMC Public Health, 17, 309.

Gall, J., Sabin, K., Frescura, L., Sabin, M. L., Erkkola, T., \& Toskin, I. (2017). Global trends of monitoring and data collection on the HIV response among key populations since the 2001 UN Declaration of Commitment on HIV/AIDS. AIDS and Behavior, 21, 3443.

Genz, A., Kirk, G., Piggott, D., Mehta, S. H., Linas, B. S., \& Westergaard, R. P. (2015). Uptake and acceptability of information and communication technology in a community-based cohort of people who inject drugs: Implications for mobile health interventions. JMIR mHealth and uHealth, 3, e70.

Gibson, D. R., Flynn, N. M., \& Perales, D. (2001). Effectiveness of syringe exchange programs in reducing HIV risk behavior and HIV seroconversion among injecting drug users. AIDS, 15, 1329-1341.

Greco, S., Ishizaka, A., Tasiou, M., \& Torrisi, G. (2019). On the methodological framework of composite indices: A review of the issues of weighting, aggregation, and robustness. Social Indicators Research, 141, 61-94.

Harm Reduction International. (2016). The global state of harm reduction 2016. London: Harm Reduction International.

Hayle, S. (2018). The politics of harm reduction: Comparing the historical development of needle exchange policy in Canada and the UK between 1985 and 1995. The Social History of Alcohol and Drugs, 32, 81-103.

Karki, P., Shrestha, R., Huedo-Medina, T. B., \& Copenhaver, M. (2016). The impact of methadone maintenance treatment on HIV risk behaviors among high-risk injection drug users: A systematic review. Evidence-based Medicine \& Public Health, 2, e1229.

Kennedy, M. C., Karamouzian, M., \& Kerr, T. (2017). Public health and public order outcomes associated with supervised drug consumption facilities: A systematic review. Current HIV/AIDS Reports, 14, 161-183.

Larney, S. (2010). Does opioid substitution treatment in prisons reduce injecting-related HIV risk behaviours? A systematic review. Addiction, 105, 216-223.

Larney, S., Peacock, A., Leung, J., Colledge, S., Hickman, M., Vickerman, P., Grebely, J., Dumchev, K. V., Griffiths, P., \& Hines, L. (2017). Global, regional, and country-level coverage of interventions to prevent and manage HIV and hepatitis $\mathrm{C}$ among people who inject drugs: A systematic review. The Lancet Global Health, 5, e1208-e1220.

Lert, F., \& Kazatchkine, M. D. (2007). Antiretroviral HIV treatment and care for injecting drug users: An evidence-based overview. International Journal of Drug Policy, 18, 255-261.

Lindo Systems. (2017). Lingo 16.0 - optimization modeling software for linear, nonlinear, and integer programming. Chicago: Lindo Systems, Inc.

Lunze, K., Raj, A., Cheng, D. M., Quinn, E. K., Bridden, C., Blokhina, E., Walley, A. Y., Krupitsky, E., \& Samet, J. H. (2014). Punitive policing and associated substance use 
risks among HIV-positive people in Russia who inject drugs. Journal of the International AIDS Society, 17.

MacArthur, G. J., Minozzi, S., Martin, N., Vickerman, P., Deren, S., Bruneau, J., Degenhardt, L., \& Hickman, M. (2012). Opiate substitution treatment and HIV transmission in people who inject drugs: Systematic review and meta-analysis. Bmj, 345, e5945.

Marks, C., Borquez, A., Jain, S., Sun, X., Strathdee, S. A., Garfein, R. S., Milloy, M., DeBeck, K., Cepeda, J. A., \& Werb, D. (2019). Opioid agonist treatment scale-up and the initiation of injection drug use: A dynamic modeling analysis. PLoS medicine, 16.

Mathers, B. M., Degenhardt, L., Ali, H., Wiessing, L., Hickman, M., Mattick, R. P., Myers, B., Ambekar, A., \& Strathdee, S. A. (2010). HIV prevention, treatment, and care services for people who inject drugs: A systematic review of global, regional, and national coverage. The Lancet, 375, 1014-1028.

Mathers, B. M., Degenhardt, L., Phillips, B., Wiessing, L., Hickman, M., Strathdee, S. A., Wodak, A., Panda, S., Tyndall, M., Toufik, A., \& Mattick, R. P. (2008). Global epidemiology of injecting drug use and HIV among people who inject drugs: A systematic review. The Lancet, 372, 1733-1745.

Montaner, J. S., Lima, V. D., Barrios, R., Yip, B., Wood, E., Kerr, T., Shannon, K., Harrigan, P. R., Hogg, R. S., \& Daly, P. (2010). Association of highly active antiretroviral therapy coverage, population viral load, and yearly new HIV diagnoses in British Columbia, Canada: A population-based study. The Lancet, 376, 532-539.

Moxham-Hall, V. L., \& Ritter, A. (2017). Indexes as a metric for drug and alcohol policy evaluation and assessment. World Medical \& Health Policy, 9, 103-126.

Organisation for Economic Co-operation and Development. (2008). Handbook on constructing composite indicators: Methodology and user guide. Paris: OECD Publishing.

Pardo, B., Kilmer, B., \& Caulkins, J. P. (2018). Assessing the evidence on supervised drug consumption sites. Santa Monica, CA: RAND.

Pinkerton, S. D. (2011). How many HIV infections are prevented by Vancouver Canada's supervised injection facility? International Journal of Drug Policy, 22, 179-183.

Pissourios, I. A. (2013). An interdisciplinary study on indicators: A comparative review of quality-of-life, macroeconomic, environmental, welfare and sustainability indicators. Ecological Indicators, 34, 420-427.

Platt, L., Jolley, E., Hope, V., Latypov, A., Vickerman, P., Hickson, F., Reynolds, L., \& Rhodes, T. (2015). HIV epidemics in the European region: Vulnerability and response. Washington, DC: World Bank Publications.

Potier, C., Laprévote, V., Dubois-Arber, F., Cottencin, O., \& Rolland, B. (2014). Supervised injection services: What has been demonstrated? A systematic literature review. Drug and Alcohol Dependence, 145, 48-68.

Reid, G., Sharma, M., \& Higgs, P. (2014). The long winding road of opioid substitution therapy implementation in South-East Asia: Challenges to scale up. Journal of public health research, 3, 204.

Sexton, T. R., Silkman, R. H., \& Hogan, A. J. (1986). Data envelopment analysis: Critique and extensions. New Directions for Program Evaluation, 1986, 73-105.

Shen, Y., Hermans, E., Brijs, T., \& Wets, G. (2013). Data envelopment analysis for composite indicators: A multiple layer model. Social Indicators Research, 114, 739-756.

Shen, Y., Hermans, E., Brijs, T., \& Wets, G. (2014). Fuzzy data envelopment analysis in composite indicator construction. In A. Emrouznejad \& M. Tavana (Eds.), Performance measurement with fuzzy data envelopment analysis (pp. 89-100). Berlin: Springer.

Shen, Y., Hermans, E., Ruan, D., Wets, G., Brijs, T., \& Vanhoof, K. (2011). A generalized multiple layer data envelopment analysis model for hierarchical structure assessment: 
A case study in road safety performance evaluation. Expert systems with applications, 38, 15262-15272.

Shen, Y., Ruan, D., Hermans, E., Brijs, T., Wets, G., \& Vanhoof, K. (2011). Modeling qualitative data in data envelopment analysis for composite indicators. International Journal of System Assurance Engineering and Management, 2, 21-30.

Stover, J. (2001). Monitoring political commitment and program effort in HIV prevention and AIDS care: The AIDS program effort index. MEASURE Evaluation Bulletin, 3, 17-21.

Strathdee, S. A., Beletsky, L., \& Kerr, T. (2015). HIV, drugs and the legal environment. International Journal of Drug Policy, 26, Supplement 1, S27-S32.

Strathdee, S. A., Hallett, T. B., Bobrova, N., Rhodes, T., Booth, R., Abdool, R., \& Hankins, C. A. (2010). HIV and risk environment for injecting drug users: The past, present, and future. The Lancet, 376, 268-284.

Tamaddon, L., Jahanshahloo, G., Lotfi, F. H., Mozaffari, M., \& Gholami, K. (2009). Data envelopment analysis of missing data in crisp and interval cases. International Journal of Mathematical Analysis, 3, 955-969.

UNAIDS. (2015a). How AIDS changed everything-MDG6: 15 years, 15 lessons of hope from the AIDS response. Geneva: UNAIDS.

UNAIDS. (2015b). On the fast-track to end AIDS. Geneva: UNAIDS.

UNAIDS. (2016). Prevention gap report. Geneva: UNAIDS.

United Nations. (2016). Political declaration on HIV and AIDS: On the fast track to accelerating the fight against HIV and to ending the AIDS epidemic by 2030. In (Vol. A/RES/70/266).

USAID, UNAIDS, WHO, \& the POLICY Project. (2003). The level of effort in the national response to HIV/AIDS: The AIDS program effort index (API) 2003 round. Washington, DC: Futures Group International.

Weir, S. S., Baral, S. D., Edwards, J. K., Zadrozny, S., Hargreaves, J., Zhao, J., \& Sabin, K. (2018). Opportunities for enhanced strategic use of surveys, medical records, and program data for HIV surveillance of key populations: Scoping review. JMIR public health and surveillance, 4, e28.

Wodak, A., \& Cooney, A. (2006). Do needle syringe programs reduce HIV infection among injecting drug users: A comprehensive review of the international evidence. Substance Use \& Misuse, 41, 777-813. 
Table 1. Conceptual Framework for HIV-PWID Policy Index (HPPI) and Selected Indicators

Domains and Indicators $\quad$ Measurement Range

1. Needle and Syringe Programs (NSPs)

1.1 NSPs Operational $0-1$

1.2 Syringes Distributed per PWID $\quad 0-565$

1.3 NSPs Operational in Prison $\quad 0-1$

1.4 Supervised Injection Facilities Operational $\quad 0-1$

1.5 National Policy Promotes Use of Clean Needles in HIV Awareness $\quad 0-1$

1.6 National Policy Promotes Needle Exchange among PWID 0-1

2. Opioid Substitution Treatment (OST)

2.1 OST Programs Operational $0-1$

2.2 OST Operational in Prison $\quad 0-1$

2.3 National Policy Promotes OST among PWID $\quad 0-1$

3. Testing and Treatment (TT)

3.1 National Policy Promotes Testing and Counseling among PWID 0-1

3.2 Antiretroviral Treatment Accessibility 2.5-5

4. Information and Education (IE)

4.1. National Policy Promotes Use of Condoms among PWID 0-1

4.2. National Policy Promotes Reproductive Health among PWID $0-1$

4.3. National Policy Promotes Stigma Reduction among PWID $0-1$

4.4. National Policy Promotes Risk Reduction among PWID $0-1$

4.5. National Policy Promotes Vulnerability Reduction among PWID 0-1

5. Monitoring and Evaluation (ME)

5.1 National HIV Monitoring and Evaluation Plan $\quad 1-3$

5.2 Quality of HIV-Related Monitoring and Evaluation $\quad 0-10$

6. Legal and Policy Climate (LPC)

6.1 Support for Harm Reduction in National Policy Documents $0-1$

6.2 Country Has National HIV Coordinating Body $0-1$

6.3 Vulnerable Populations Involved in HIV Policy Development $0-1$

6.4 Country Has No HIV-Related Travel Restrictions $\quad 0-1$

6.5 National Strategy Addresses PWID $0-1$

6.6 PWID Identified as Target Group for HIV Programming $\quad 0-1$

6.7 Nondiscrimination Laws Protect PWID $\quad 0-1$

6.8 Laws Support Effective HIV Response among PWID $\quad 0-1$

6.9 Extent of Harm Reduction Resources for PWID $1-4$

Note: See Appendix I for detailed definitions and sourcing information. 
Table 2. HIV-PWID Policy Index (HPPI) Results

\begin{tabular}{|c|c|c|c|c|}
\hline \multirow[b]{2}{*}{ Country } & \multirow[b]{2}{*}{ Region } & \multirow[b]{2}{*}{ Subregion } & \multicolumn{2}{|c|}{$\begin{array}{c}\text { Index Scores for } \\
\text { Indifferent and } h=0.5\end{array}$} \\
\hline & & & Score & Ranking \\
\hline Spain & Europe & West and Central Europe & 0.9883 & 1 \\
\hline Switzerland & Europe & West and Central Europe & 0.9822 & 2 \\
\hline Luxembourg & Europe & West and Central Europe & 0.9703 & 3 \\
\hline Moldova & Europe & Eastern Europe & 0.9701 & 4 \\
\hline Kyrgyzstan & Asia & Central Asia & 0.9452 & 5 \\
\hline Armenia & Asia & Central Asia & 0.9253 & 6 \\
\hline Norway & Europe & West and Central Europe & 0.9213 & 7 \\
\hline France & Europe & West and Central Europe & 0.9209 & 8 \\
\hline Canada & Americas & North America & 0.9176 & 9 \\
\hline Australia & Oceania & Oceania & 0.9056 & 10 \\
\hline India & Asia & South Asia & 0.8963 & 11 \\
\hline Montenegro & Europe & South Eastern Europe & 0.8846 & 12 \\
\hline Portugal & Europe & West and Central Europe & 0.8833 & 13 \\
\hline Mauritius & Africa & East Africa & 0.8814 & 14 \\
\hline Sweden & Europe & West and Central Europe & 0.8812 & 15 \\
\hline Estonia & Europe & West and Central Europe & 0.8804 & 16 \\
\hline Morocco & Africa & North Africa & 0.8796 & 17 \\
\hline Iran & Asia & Southwest Asia & 0.8794 & 18 \\
\hline Vietnam & Asia & East and Southeast Asia & 0.8788 & 19 \\
\hline Poland & Europe & West and Central Europe & 0.8766 & 20 \\
\hline Indonesia & Asia & East and Southeast Asia & 0.8766 & 21 \\
\hline Germany & Europe & West and Central Europe & 0.8764 & 22 \\
\hline Macau & Asia & East and Southeast Asia & 0.8755 & 23 \\
\hline Serbia & Europe & South Eastern Europe & 0.8738 & 24 \\
\hline Tajikistan & Asia & Central Asia & 0.8726 & 25 \\
\hline Slovenia & Europe & West and Central Europe & 0.8718 & 26 \\
\hline Lithuania & Europe & West and Central Europe & 0.8705 & 27 \\
\hline Latvia & Europe & West and Central Europe & 0.8697 & 28 \\
\hline Bulgaria & Europe & South Eastern Europe & 0.8697 & 29 \\
\hline Georgia & Asia & Central Asia & 0.8678 & 30 \\
\hline Romania & Europe & South Eastern Europe & 0.8344 & 31 \\
\hline Italy & Europe & West and Central Europe & 0.8321 & 32 \\
\hline Netherlands & Europe & West and Central Europe & 0.8292 & 33 \\
\hline Denmark & Europe & West and Central Europe & 0.8280 & 34 \\
\hline Cambodia & Asia & East and Southeast Asia & 0.8268 & 35 \\
\hline Tunisia & Africa & North Africa & 0.8241 & 36 \\
\hline China & Asia & East and Southeast Asia & 0.8162 & 37 \\
\hline Myanmar & Asia & East and Southeast Asia & 0.8137 & 38 \\
\hline Bangladesh & Asia & South Asia & 0.8064 & 39 \\
\hline Slovakia & Europe & West and Central Europe & 0.8036 & 40 \\
\hline Hungary & Europe & West and Central Europe & 0.8033 & 41 \\
\hline Kazakhstan & Asia & Central Asia & 0.7989 & 42 \\
\hline Tanzania & Africa & East Africa & 0.7964 & 43 \\
\hline Nepal & Asia & South Asia & 0.7958 & 44 \\
\hline Azerbaijan & Asia & Central Asia & 0.7955 & 45 \\
\hline Afghanistan & Asia & Southwest Asia & 0.7951 & 46 \\
\hline Ukraine & Europe & Eastern Europe & 0.7940 & 47 \\
\hline Belarus & Europe & Eastern Europe & 0.7921 & 48 \\
\hline Senegal & Africa & West and Central Africa & 0.7906 & 49 \\
\hline Mexico & Americas & North America & 0.7899 & 50 \\
\hline
\end{tabular}




\begin{tabular}{|c|c|c|c|c|}
\hline Kenya & Africa & East Africa & 0.7896 & 51 \\
\hline Thailand & Asia & East and Southeast Asia & 0.7872 & 52 \\
\hline United Kingdom & Europe & West and Central Europe & 0.7841 & 53 \\
\hline Belgium & Europe & West and Central Europe & 0.7836 & 54 \\
\hline Greece & Europe & West and Central Europe & 0.7828 & 55 \\
\hline Czech Republic & Europe & West and Central Europe & 0.7750 & 56 \\
\hline United States & Americas & North America & 0.7668 & 57 \\
\hline Uzbekistan & Asia & Central Asia & 0.7554 & 58 \\
\hline Russia & Europe & Eastern Europe & 0.7449 & 59 \\
\hline Egypt & Africa & North Africa & 0.7445 & 60 \\
\hline Philippines & Asia & East and Southeast Asia & 0.7276 & 61 \\
\hline $\begin{array}{l}\text { Dominican } \\
\text { Republic }\end{array}$ & Americas & Caribbean & 0.7190 & 62 \\
\hline Malta & Europe & West and Central Europe & 0.7097 & 63 \\
\hline Finland & Europe & West and Central Europe & 0.6994 & 64 \\
\hline $\begin{array}{l}\text { Bosnia and } \\
\text { Herzegovina }\end{array}$ & Europe & South Eastern Europe & 0.6917 & 65 \\
\hline Lebanon & Asia & Near and Middle East & 0.6890 & 66 \\
\hline Albania & Europe & South Eastern Europe & 0.6806 & 67 \\
\hline South Africa & Africa & Southern Africa & 0.6799 & 68 \\
\hline Pakistan & Asia & Southwest Asia & 0.6795 & 69 \\
\hline Malaysia & Asia & East and Southeast Asia & 0.6785 & 70 \\
\hline Brazil & Americas & South America & 0.6759 & 71 \\
\hline Paraguay & Americas & South America & 0.6706 & 72 \\
\hline Cyprus & Europe & West and Central Europe & 0.6519 & 73 \\
\hline Croatia & Europe & South Eastern Europe & 0.6393 & 74 \\
\hline DR Congo & Africa & West and Central Africa & 0.6384 & 75 \\
\hline Argentina & Americas & South America & 0.6362 & 76 \\
\hline New Zealand & Oceania & Oceania & 0.6147 & 77 \\
\hline Macedonia & Europe & South Eastern Europe & 0.5700 & 78 \\
\hline Colombia & Americas & South America & 0.4941 & 79 \\
\hline Turkey & Europe & South Eastern Europe & 0.4567 & 80 \\
\hline Uruguay & Americas & South America & 0.4541 & 81 \\
\hline Jordan & Asia & Near and Middle East & 0.4465 & 82 \\
\hline Algeria & Africa & North Africa & 0.3993 & 83 \\
\hline Madagascar & Africa & East Africa & 0.3910 & 84 \\
\hline Nigeria & Africa & West and Central Africa & 0.3707 & 85 \\
\hline Ghana & Africa & West and Central Africa & 0.3704 & 86 \\
\hline Togo & Africa & West and Central Africa & 0.3591 & 87 \\
\hline Sri Lanka & Asia & South Asia & 0.3585 & 88 \\
\hline Côte d'Ivoire & Africa & West and Central Africa & 0.3293 & 89 \\
\hline Saudi Arabia & Asia & Near and Middle East & 0.3159 & 90 \\
\hline Kuwait & Asia & Near and Middle East & 0.3104 & 91 \\
\hline Liberia & Africa & West and Central Africa & 0.3080 & 92 \\
\hline Guatemala & Americas & Central America & 0.2815 & 93 \\
\hline Mozambique & Africa & Southern Africa & 0.2808 & 94 \\
\hline Honduras & Americas & Central America & 0.2789 & 95 \\
\hline Seychelles & Africa & East Africa & 0.2470 & 96 \\
\hline Libya & Africa & North Africa & 0.2271 & 97 \\
\hline Maldives & Asia & South Asia & 0.2098 & 98 \\
\hline Bahrain & Asia & Near and Middle East & 0.1970 & 99 \\
\hline Oman & Asia & Near and Middle East & 0.1966 & 100 \\
\hline Benin & Africa & West and Central Africa & 0.1846 & 101 \\
\hline Syria & Asia & Near and Middle East & 0.1739 & 102 \\
\hline
\end{tabular}




\begin{tabular}{lllll} 
Cape Verde & Africa & West and Central Africa & 0.0972 & 103 \\
Japan & Asia & East and Southeast Asia & 0.0942 & 104 \\
Nicaragua & Americas & Central America & 0.0935 & 105 \\
\hline
\end{tabular}


Table 3. HIV-PWID Policy Index (HPPI) Scores

\begin{tabular}{lccc} 
by Region & Mean & Min & Max \\
\hline Region & 0.81 & 0.46 & 0.99 \\
Europe & 0.83 & 0.74 & 0.97 \\
Eastern Europe & 0.72 & 0.46 & 0.88 \\
South Eastern Europe & 0.84 & 0.65 & 0.99 \\
West and Central Europe & 0.66 & 0.09 & 0.95 \\
Asia & 0.85 & 0.76 & 0.95 \\
Central Asia & 0.74 & 0.09 & 0.88 \\
East and Southeast Asia & 0.33 & 0.17 & 0.69 \\
Near and Middle East & 0.61 & 0.21 & 0.90 \\
South Asia & 0.78 & 0.68 & 0.88 \\
Southwest Asia & 0.56 & 0.09 & 0.92 \\
Americas & 0.72 & 0.72 & 0.72 \\
Caribbean & 0.22 & 0.09 & 0.28 \\
Central America & 0.82 & 0.77 & 0.92 \\
North America & 0.59 & 0.45 & 0.68 \\
South America & 0.76 & 0.61 & 0.91 \\
Oceania & 0.50 & 0.10 & 0.88 \\
Africa & 0.62 & 0.25 & 0.88 \\
East Africa & 0.61 & 0.23 & 0.88 \\
North Africa & 0.48 & 0.28 & 0.68 \\
Southern Africa & 0.38 & 0.10 & 0.79 \\
West and Central Africa & 0.67 & 0.09 & 0.99 \\
\hline Global & & &
\end{tabular}




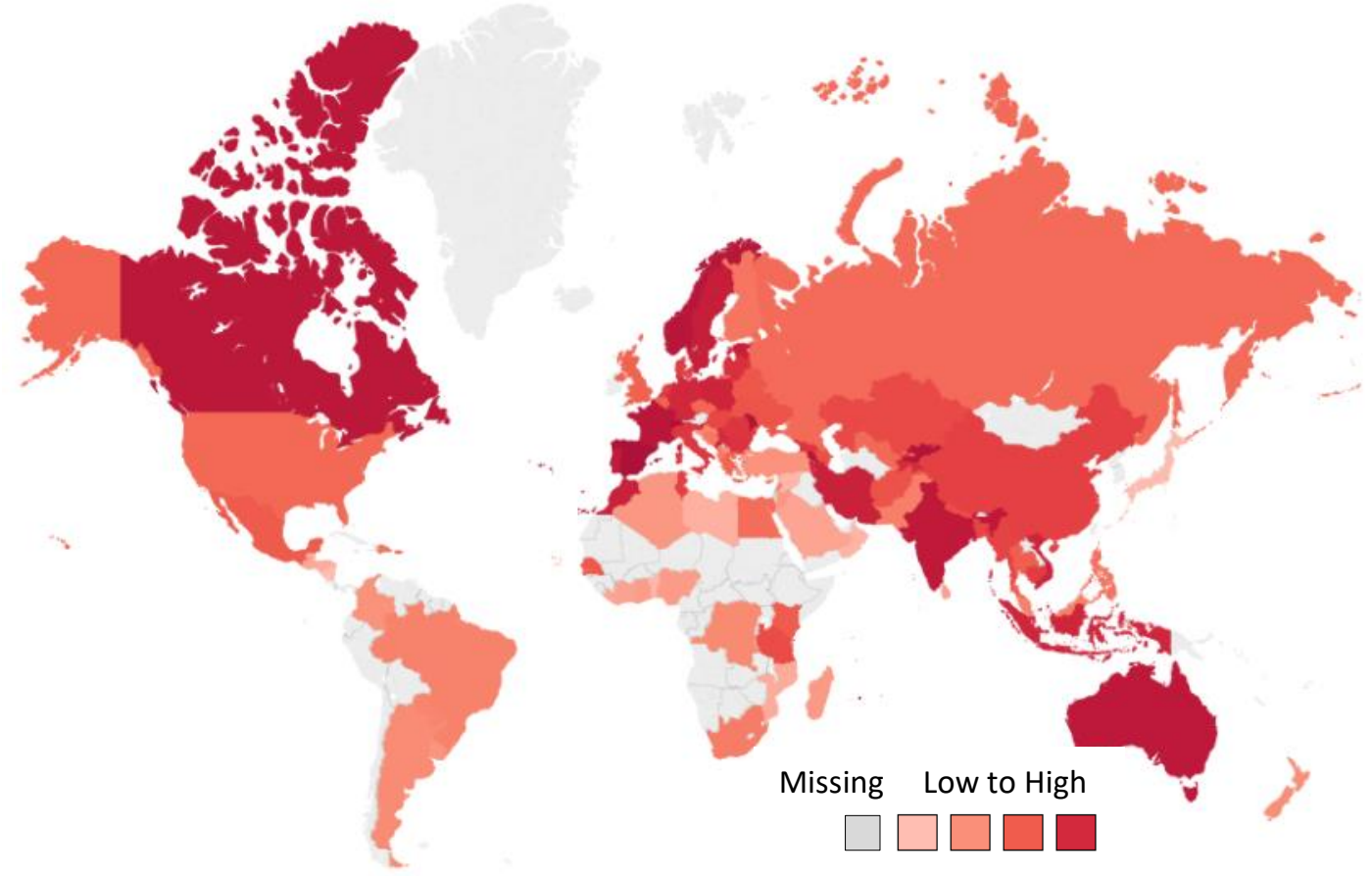

Figure 1. HPPI Scores Indicating Commitment to HIV Programming among PWID 


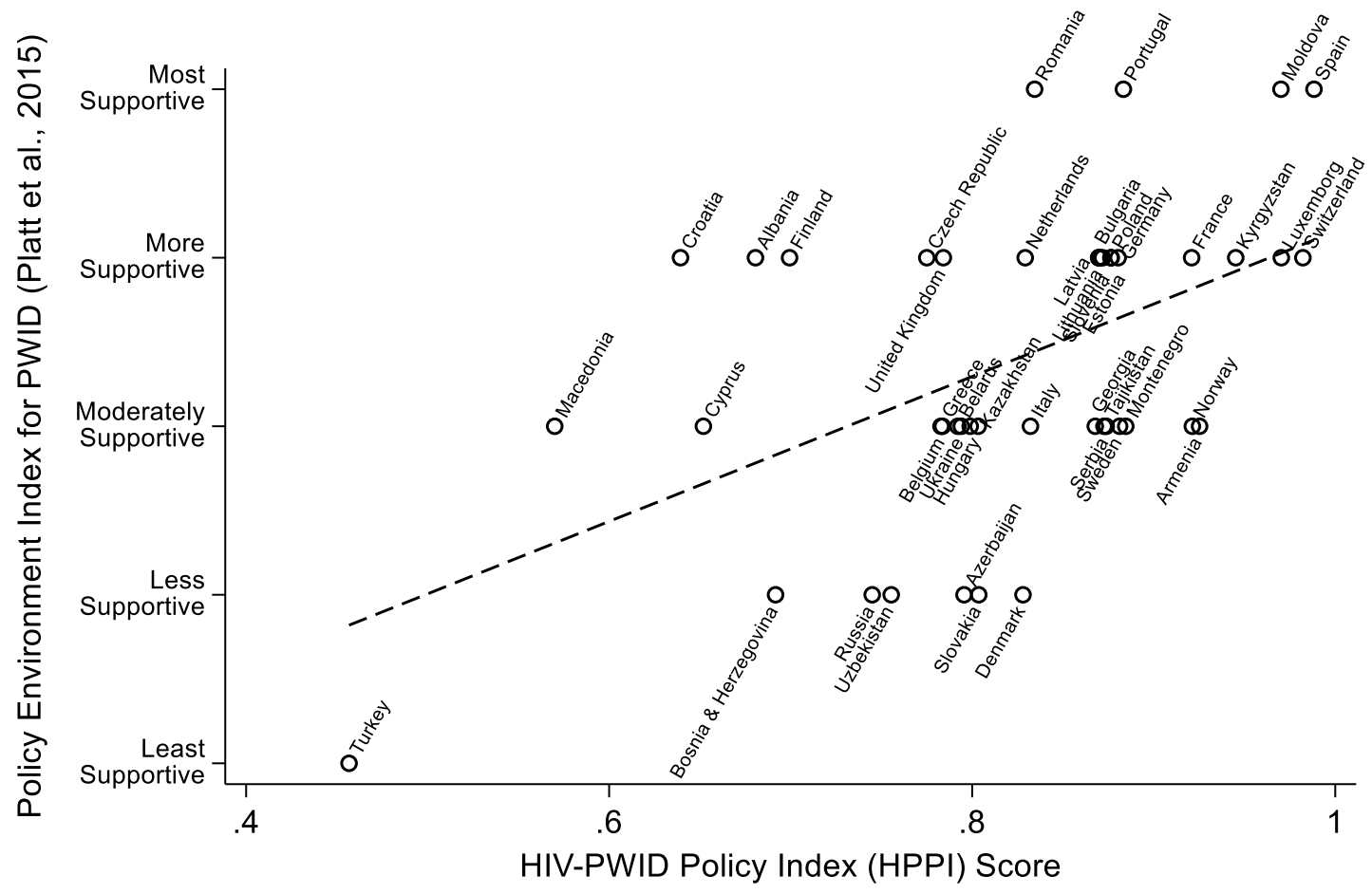

Figure 2. Comparison of HPPI Results with Platt et al. (2015) for 44 European Countries 